\title{
Filhos de Macunaima ou: não sou índio, sou macuxi e meu nome é...
}

Apresentação de Lucia Sá ${ }^{2}$

Fotos de Devair Fiorotti ${ }^{2}$

Guiado, entre outros, por Manduca (um pajé yeakuana) e Mayuluaípu (um intérprete taurepang), o alemão Theodor KochGrünberg realizou, em 1911, uma extensa viagem pelo território do circum-Roraima, na tríplice fronteira entre o Brasil, a Venezuela e a Guiana, a qual ficou registrada nos cinco volumes da coleção Do Roraima ao Orinoco, publicados em alemão entre 1917 e 1924. O primeiro e o terceiro, respectivamente o diário de viagem e um livro de anotações etnográficas, incluem várias fotografias em branco e preto, ilustrando atividades diárias dos grupos indígenas por ele visitados. Nessas fotos, indígenas taurepang podem ser vistos ralando mandioca ou caçando com zarabatana, assim como crianças da mesma etnia brincando de cama de gato, para citar apenas alguns exemplos. Mas é no quinto volume, exclusivamente de fotos, que se pode medir a importância do registro imagético para o trabalho etnográfico de Koch-Grünberg. As fotos desse volume, de excelente qualidade para a época, retratam famílias, grupos e indivíduos macuxi, taurepang, arekuná, wapixana, e ingaricó, além de outras etnias da região do Orinoco.

Algumas fotografias apresentam famílias ou grupos acompanhadas de legendas descritivas como "homens e jovens taurepang" ou "mulheres e jovens macuxi" diante de malocas e marcos geográficos da região, mas a grande maioria consiste de torsos de indivíduos posando de frente para a câmara e de perfil. Tanto os grupos como os indivíduos aparecem em trajes típicos, isto é, com o torso nu ou adornado de colares e, em alguns casos, com cocares ou outros enfeites de miçangas ou de plumas. No início do volume, alguns indivíduos são contemplados com nomes pessoais e descrições adicionais do tipo "inteligente, energético", mas a grande maioria é apenas identificada

\footnotetext{
1 Doutora em literatura comparada e professora da Universidade de Manchester, Oxford, Manchester, United Kingdom. E-mail: lucia.sa@manchester.ac.uk

${ }^{2}$ Doutor em literatura e professor da Universidade Estadual de Roraima (UERR) e da Universidade Federal de Roraima (UFRR), Boa Vista, RR, Brasil. E-mail: devair.a.fiorotti@gmail.com
} 
com o gênero, a idade, a etnia, e a localização (Koch-Grünberg, 1923). Em outras palavras, as fotos servem ao claro propósito de descrever os grupos étnicos da região para a ciência da época, ligando detalhes biométricos facilmente deduzíveis das imagens (por exemplo a altura, a proporção dos membros, o tamanho relativo do crânio etc.) com características intelectuais ou de personalidade.

Se, de acordo com Koch-Grünberg (2005), a maioria dos indivíduos via com prazer o ato de ser fotografado (porque, entre outras razões, as pessoas que posavam eram remuneradas com bebida, tabaco ou outros regalos) e não tinha medo da câmera, os retratos em si pouco revelam desse prazer: página após página, o que se vê são indivíduos em poses idênticas, de frente ou de lado para a câmera, com pouca ou nenhuma expressão. A repetição e a semelhança entre as fotografias faz com que a descrição dos grupos étnicos deixe de importar, e o que o conjunto de retratos acaba por revelar é o estereótipo do índio genérico amazônico: seminu (isto é, "selvagem" e disponível), desajeitado frente a câmera (isto é, incongruente com a modernidade da fotografia) e atemporal em sua vocação de objeto de estudo científico. Como observa Morgan F. Bell (2011), com referência aos Estados Unidos, fotografias de ameríndios feitas no final do século XIX e princípios do século XX tiveram um papel fundamental na perpetuação da imagem estereotipada do "índio". Algumas das poses típicas dessas fotos incluíam o olhar vazio ou inexpressivo de frente para a câmera ou levemente desviado; poses ameaçadoras no caso dos homens; ou de submissão tristonha, no caso de homens e mulheres; torso nu, no caso de homens; e seios à mostra no caso de mulheres. Os seios desnudos, embora naturais no dia a dia de mulheres indígenas de várias etnias, adquiriam um sentido distinto quando essas mulheres posavam para imagens que iam ser consumidas por não indígenas: nesse caso, a mensagem quase inevitável, ainda de acordo com Bell, era a de disponibilidade, o que por sua vez servia de metáfora para a suposta disponibilidade das terras indígenas de forma geral.

As fotos de Devair Fiorotti incluídas neste pequeno ensaio foram tiradas na comunidade Macuxi Aleluia, antiga comunidade do Mel, perto da Serra do Mel, mencionada inúmeras vezes por Koch-Grünberg (1923) na identificação de suas fotos, durante a sua estada na região do circum-Roraima. O preto e branco, o local onde foram tiradas, e a identidade dos modelos (indígenas macuxi) estabelecem uma inevitável 
relação de continuidade com o trabalho fotográfico feito há mais de 100 anos pelo naturalista alemão. As crianças retratadas nas fotos são, pois, "filhas de Macunaima" em dois sentidos: primeiro, porque Macunaima é o deus/demiurgo tradicionalmente celebrado em sua cultura - o mesmo demiurgo transformador dos arekunas que protagoniza várias das narrativas incluídas no segundo volume de Do Roraima do Orinoco, e que se transformaria, por sua vez (graças ao trabalho de KochGrünberg), no protagonista do romance modernista de Mário de Andrade, Macunaíma; e segundo, porque elas são descendentes diretas dos macuxis visitados e retratados por Koch-Grünberg em sua obra.

Ao mesmo tempo, as fotos deste ensaio colocam-se, já a partir do título, como críticas ao conceito de índio genérico tão prevalente ainda em discursos sobre os povos originários no Brasil e que Koch-Grünberg, através de suas fotos mais "científicas", colaborou por perpetuar. Em vez do apelativo "índio", as crianças do título pedem para ser identificadas com sua etnia macuxi e os seus nomes individuais. Além disso, as fotos em si não poderiam ser mais diferentes da tradição fotográfica acima descrita por Bell e vista no quinto volume do naturalista alemão. Primeiro, porque as crianças fotografadas por Devair se sentem obviamente cômodas diante da câmera, encarando diretamente a lente e devolvendo olhares desafiadores, risonhos, ou inquisitivos. Como outras crianças, elas são fascinadas por tecnologia: quando perguntei a Devair se elas tinham visto as fotos, ele respondeu que elas tinham visto tudo imediatamente, pois adoram mexer na câmera e no computador. Em várias das fotos, as crianças aparecem interagindo umas com as outras, carinhosas, sapecas, confiantes.

É evidente que, graças à leveza e à flexibilidade dos equipamentos fotográficos atuais, esses modelos mirins não têm que posar por vários minutos em posições determinados pelo artista: são eles que escolhem como posar, o que fazer diante da câmera, como se comportar. O resultado são fotos que diferem muito umas das outras, porque as crianças, além de nomes, têm personalidades, desejos, irritações. A profunda beleza dessas fotos deve muito à técnica de Devair, isto é, à perfeita utilização de luz e sombra, à excelente composição que dá sempre a impressão de espontaneidade, à naturalidade das cenas. Mas deve também ao encanto das crianças macuxi, tão à vontade umas com as outras e com o fotógrafo, tão em casa com elas mesmas. São fotos de crianças sendo crianças, e é precisamente na capacidade de retratar 
crianças que reside o talento do autor destas imagens. Mas são também, não podemos nos esquecer, fotos de crianças macuxi, que nasceram e estão crescendo em terra macuxi, na comunidade em que cresceram seus pais, tios e avós, e onde seus tataravós, possivelmente, conheceram o alemão Theodor Koch-Grünberg.

De torso nu ou de roupas ocidentais, mexendo em câmeras, brincando com objetos tradicionais, ou escrevendo seus nomes tão brasileiros em tiras de papel, são crianças que provam que os macuxi, além do passado testemunhado nos textos e fotos de Koch-Grünberg, têm presente e têm futuro. Ao apontar o dedo diretamente para a câmera, num gesto ambíguo que tanto parece mostrar a lente para a bebê no seu colo como talvez brincar com o fotógrafo, a jovem macuxi Julielly inverte a célebre metáfora associada por Susan Sontag (1978) ao papel colonizador da fotografia: a câmera como a sublimação da arma, que violenta o que vê. Longe de se reduzir a um objeto passivo à mira da lente, Julielly interage com o fotógrafo, denuncia sua presença e o traz para dentro da foto, dona e agente que é de sua própria imagem.

\section{Referências}

BELL, Morgan F. (2011) Some thoughts on "taking" pictures. Imaging "Indians" and the counter-narratives of visual sovereignty. Great Plains Quarterly, Lincoln, v. 31, n. 2, p. 85-104, Spring.

KOCH-GRÜNBERG, Theodor (1923). Vom Roraima zum Orinoco. Berlin: Dietrich Reimer. v. 5. Disponível em: <https://goo.gl/sU5Zgi>. Acesso em: 8 out. 2017.

KOCH-GRÜNBERG, Theodor (2005). Do Roraima ao Orinoco. Tradução de Cristina Alberts-Franco. São Paulo: Unesp. v. 1.

SONTAG, Susan (1978). On photography. Allen Lane: Penguin. 


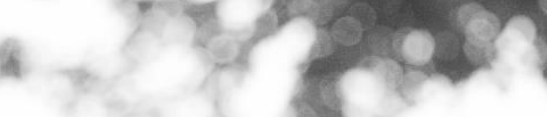

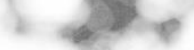

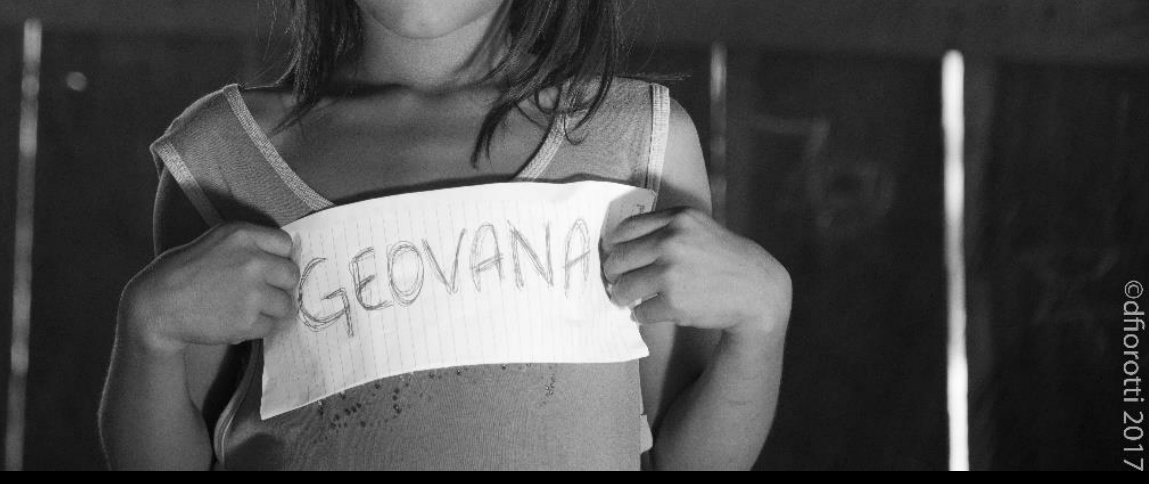

I Geovana, makuxi, Comunidade Aleluia 
Marta, Jadson, Josefa e Cleiciane, irmãos makuxi, Comunidade Aleluia
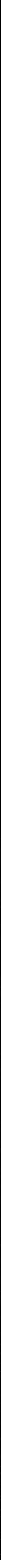

Cleisiane, Tamara, Raykener, Juliel, Jelie e Vanessa, crianças macuxi, Comunidade Aleluia | 


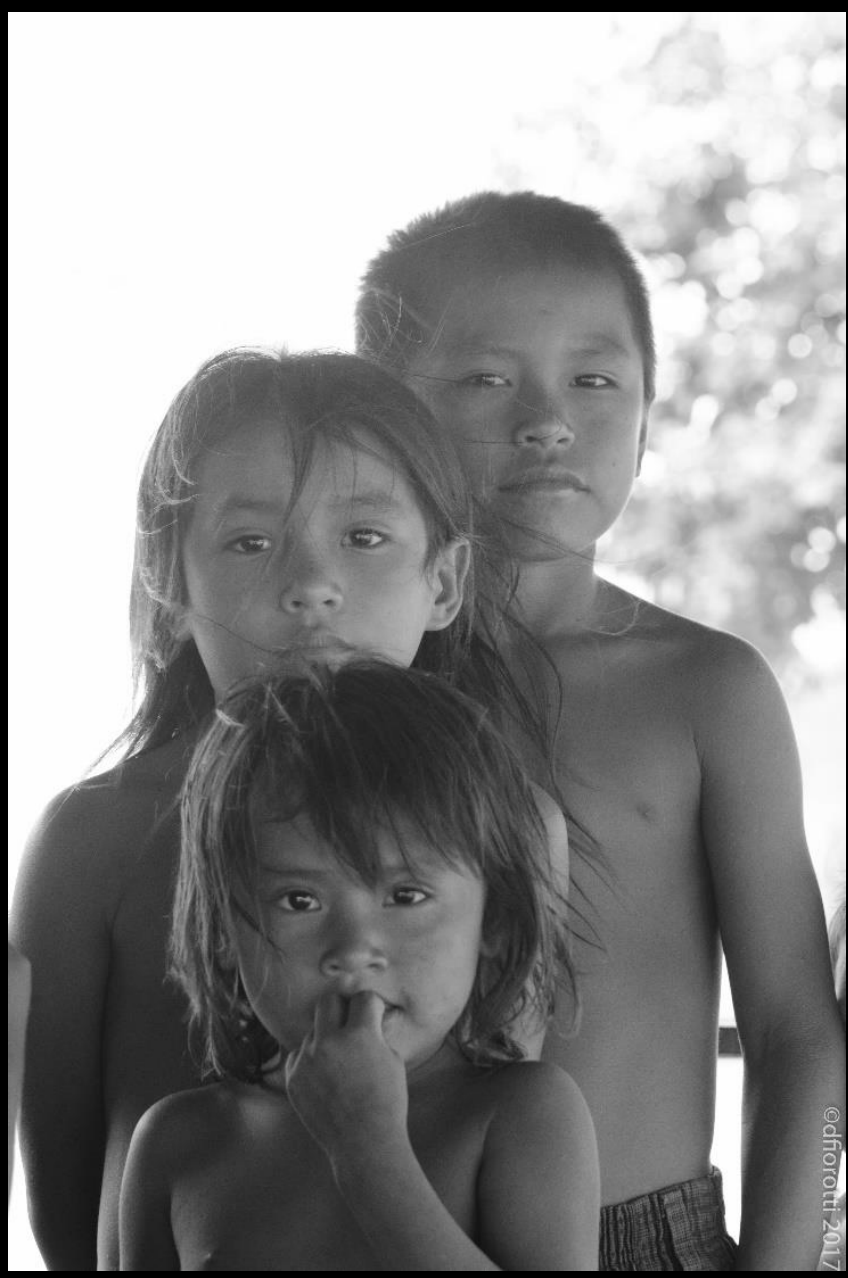

Jadson, Cleisiane e Josefa, irmãos makuxi, Comunidade Aleluia ～| 

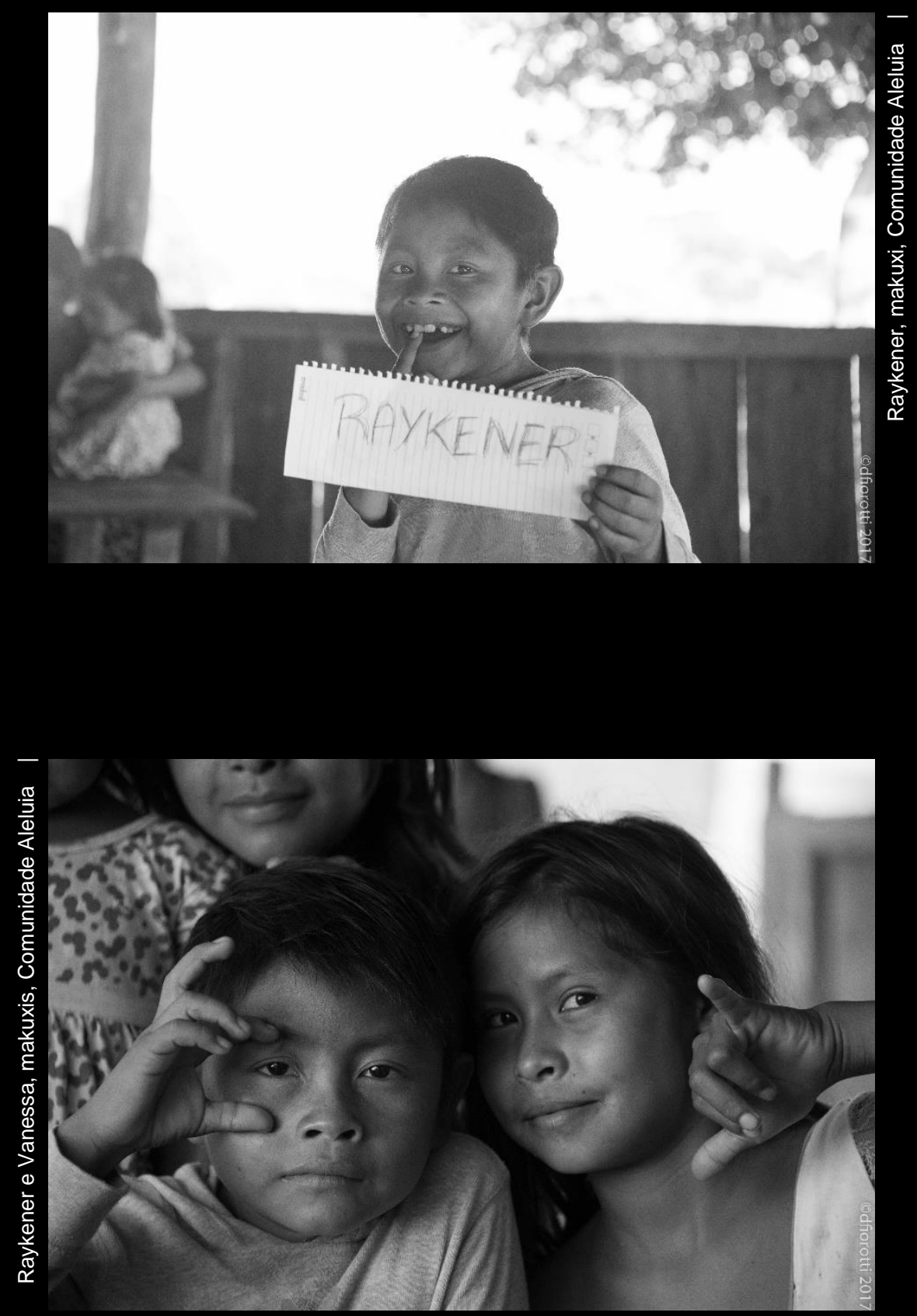

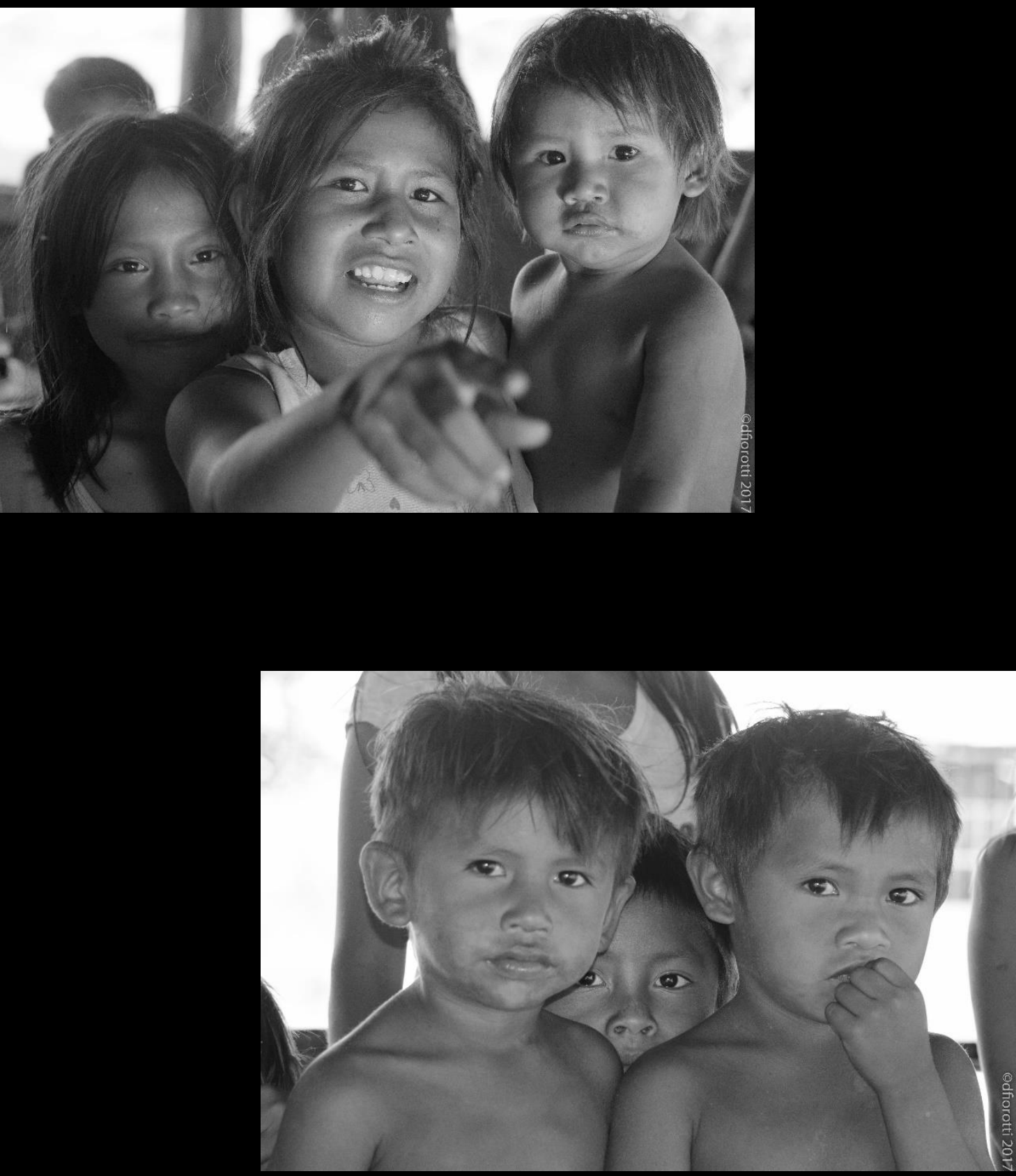